Araştırma Makalesi - Research Article

\title{
Harmonik Sinyallerin Yük Tanımadaki Başarısının İncelenmesi ve Yeni Bir Model Önerisi
}

\author{
Emre Akarslan ${ }^{1 *}$, Rasim Doğan ${ }^{2}$ \\ Geliş / Received: $12 / 05 / 2020$ \\ Revize / Revised: 12/06/2020 \\ Kabul / Accepted: 17/06/2020
}

\section{$\ddot{\text { öz }}$}

Günümüzde gelişen teknoloji ve akıllı sistemlerin yaygınlaşması ile birlikte yük tarafının kontrolü önemli bir konu haline gelmiştir. Özellikle akıllı evlerde herhangi bir anda sistemde mevcut yüklerin doğru bir şekilde belirlenmesi, onların yönetilebilmesi açısından kritiktir. Bu çalışmada, harmonik akım sinyallerini girdi olarak kullanan yeni bir yük tanıma modeli önerilmiştir. 1000W 1sıtıc1, 1200W 1sıtıc1, 1000W süpürge, 2200W su 1sıtıcısı ve 2100W ütünün elektrik yükü olarak seçildiği çalışmada, bu yüklerin bireysel ya da çeşitli kombinasyonlarda birlikte kullanıldığı durumlarda akım ve gerilim sinyalleri toplanmıştır. Sonrasında bu sinyallerden çıkarılan öznitelikler ve yapay sinir ağları kullanılarak, sistemde herhangi bir anda bulunan yükler belirlenmeye çalışılmıştır. Son olarak öznitelik olarak kullanılan her bir harmonik akım sinyalinin yük tanıma başarısına etkisi incelenmiş ve en etkili öznitelikler belirlenmiştir. Gerçekleştirilen simülasyon sonuçları önerilen modelin yük tanımada çok başarılı sonuçlar sağladığını göstermiştir.

Anahtar Kelimeler- Yük tanıma, Harmonik bileşenler, Yapay sinir ăgları.

\footnotetext{
1*Sorumlu yazar iletişim: e.akarslan@gmail.com (https://orcid.org/0000-0002-5918-7266)

Elektrik Mühendisliği, Afyon Kocatepe Üniversitesi, ANS Kampüsü, 03200, Afyonkarahisar, Türkiye

2İletişim: rasimdogan@aku.edu.tr (https://orcid.org/0000-0003-2122-9528)

Elektrik Mühendisliği, Afyon Kocatepe Üniversitesi, ANS Kampüsü, 03200, Afyonkarahisar, Türkiye
} 


\title{
The Investigation of Harmonic Signals Success on Load Identification and A New Model Proposal
}

\begin{abstract}
With the development of technology and smart systems, the control of the demand side has become an important issue today. Especially in smart homes, accurate determination of the loads presented in the system at any time is critical in terms of managing them. In this study, a novel load identification model is proposed that uses harmonic current signals as input. $1000 \mathrm{~W}$ heater, $1200 \mathrm{~W}$ heater, $1000 \mathrm{~W}$ vacuum cleaner, $2200 \mathrm{~W}$ kettle and $2100 \mathrm{~W}$ iron are selected as electrical loads, and their current and voltage signals are recorded when these loads are used in individual or various combinations. Then, by using the features extracted from these signals and artificial neural networks, the loads presented at any time in the system are determined. Finally, the effect of each harmonic current signal used as a feature on load identification success is examined and the most effective features are determined. The simulation results present that the proposed model provides very successful results in load identification.
\end{abstract}




\section{GíRiş}

Teknolojinin gelişimi ve nüfus artışı ile artan enerji talebi, aynı anda farklı üreticilerin sisteme dahil olduğu ve tüketim tarafının da yönetilebildiği akıllı şebekelerin daha da ön plana çıkmasına neden olmuştur. Akıllı şebekelerde talep tarafının yönetilmesinin bir parçası da şebekede bulunan yüklerin doğru belirlenmesidir. Özellikle akıllı evlerin yaygınlaştığı günümüzde, yükün doğru bir şekilde tanımlanabilmesi daha da önemli hale gelmiştir. Bu amaçla yükün izlenmesi (load monitoring) gerekir ki, yük izlemenin önemli aşamalarından bir tanesi de izlenen yükün doğru bir şekilde belirlenmesidir. Bu alanda referans çalışmalardan bir tanesi Hart [12] tarafından önerilen Müdahaleci olmayan cihaz yükü izleme (Non-intrusive Appliance Load Monitoring) algoritmasıdır. Bu çalışmada On/Off durumlarında güç tüketimindeki değişimlerin izlenerek, burada fark oluşturan yüklerin belirlenmesi kümelenme (clustering) algoritması ile açıklanmıştı.". Sonrasında literatürde bu alanda farklı strateji ve yöntemlerin kullanıldığı çok sayıda çalışma gerçekleştirilmiştir. [1]'de, tak-çalışıı yükleri tanımak için Kontrollü Bireysel Organizasyon Haritası (Supervised Self Organisation Map) ve Bayes yaklaşımını (Bayesian approach) kullanmayı önermişlerdir. Çalışmada öznitelik olarak rms akımı, 3. ve 5. harmonik akımı, güç faktörü, tepe (crest) faktörü ve toplam harmonik bozulma (THD) değerleri kullanılmıştır. Yük olarak LCD monitör, LCD TV ve LED TV gibi yüklerden elde edilmiş sinyaller üzerinde yapılan çalışmalarda başarılı sonuçlar elde edilmiştir. [2]'de, yöntem olarak Yapay Sinir Ağlarını kullanmışlardır. Parseval teoremiyle hesaplanan dalgacık dönüşüm katsayılarının güç spektrumu öznitelik olarak kullanılmış, Klima, TV, fırın, çamaşır makinesi vb. gibi bazı konut yükleri tanımlanmaya çalışılmışır. Seçilen özniteliklerin geri yayılım algoritmasını kullanan yapay sinir ağları ile kullanıldığı deneyler sonucunda, önerilen yöntemin böyle çalışmalar için uygun olacağı değerlendirilmiştir. [3]'te bir cihaz modeli oluşturmak için güç sinyalini kullanmışlardır. Geliştirilen tanıma modeli, öznitelik çıkarma, seçme ve sınıflandırma aşamalarından oluşmaktadır. Çalışmada öznitelik olarak, aktif ve reaktif güçteki değişimler, aktif güçteki geçici rejim (transients) ile geçici rejimlerin iki temel bileşen eksenine iz düşümleri kullanılmış ve REDD ile BLUED veri seti verileri üzerinde başarılı sonuçlar elde edilmiştir. [4]'te, kuadratik (quadratic) programlamadan faydalanmışlardır. Çalışmada, fırın, vantilatör, süpürge, masa lambası, mikrodalga fırın, çamaşır makinesi ve televizyon gibi mesken yüklerini tanımak için, aktif-reaktif güç, etkin (rms) akım değeri, tepe faktörü ile akım-gerilim eğrisinden elde edilen geometrik bilgiler gibi çeşitli öznitelikler kullanılmıştır. Önerilen yöntem ile \%90 üzerinde bir tanıma doğruluğu değerine ulaşıldığı rapor edilmiştir. [15]'te periyodograma dayalı yeni bir yük tanıma algoritması önermişlerdir. Yapılan çalışmada elektrikli cihazların karakteristik modellerinin seçimi ve belirlenmesi için teorik bir analiz gerçekleştirmişler, simülasyon çalışmaları ile de analizlerini test etmişlerdir. Bu yöntem, sistem karmaşıklığını büyük ölçüde basitleştirebilir ve yük tanıma başarısını artırabilir. Yapılan çalışmada elde edilen sonuçlar, bu alanda yapılacak çalışmalar için bir temel oluşturabilir. [7]'de Faktöriyel Gizli Markov Model ile Yinelemeli Alt Dizi Dinamik Zaman Çözgü (Iterative Subsequence Dynamic Time Warping) yöntemlerinin kombinasyonundan oluşan hibrit bir yöntem önermişlerdir. Güç tüketiminin öznitelik olarak kullanıldığı çalışmada 5 farklı cihaz üzerinden yapılan çalışmalarda, başarılı tanıma performansı elde edilmiştir. [8]'de güç dalga formunun geçici rejimini öznitelik olarak kullanmayı önermişlerdir. Önerilen yöntemde dinamik zaman çözgü (DTW) algoritması ile zaman serileri arasındaki benzerlik ortaya koyulurken, cihazı tanımlamak için en yakın komşu geçici tanımlama (nearest neighbour transient identification) yöntemi kullanılır. Genel (public) veri setleri üzerinde yapılan testlerde çok başarılı sonuçlar elde edildiği belirtilmiştir. Ayrıca yöntemin uygulamasının kolaylığı ve işlem karmaşıklığının düşüklüğü, yöntemin başarılı unsurları olarak rapor edilmiştir. [16]'da bir trafo merkezi tüketici grubundan, dengesiz bir yükün tanınması için yeni bir yöntem sunmuşlardır. Bu şekilde elde edilen bilgi aynı zamanda eşdeğer elektrik şeması oluşturma işlemini kolaylaştıracak enformasyon sağlar. [14]'te çok etiketli sınıflandırma (multi-label classification) yaklaşımının başarısını incelemiş̧lerdir. Bir evden toplanan akım, aktif-reaktif güç, güç faktörü gibi elektriksel nicelikler, öznitelik olarak kullanılmıştır. Karar ağaçları (Decision tree) sınıflandırıcı olarak seçilmiş, su 1sıtıcısı, klima gibi yüksek güçlü cihazlar ile aydınlatma cihazları üzerinde deneyler yapılmıştır. Yük tanıma başarısı farklı cihaz türleri için farklı olmakla beraber, kabul edilebilir doğrulukta tanıma sağlanmıştır. [9]'da yük tanıma doğruluğunu artırmak için çözünürlüğ̈̈ artırılmış admitans (resolution enhanced admittance) adı verilen admitans temelli yük işareti kullanılmasını önermişlerdir. Akım ve gerilim sinyalleri ile harmonik sinyallerinin yanında, yük admitansındaki faz bilgisinin de öznitelik olarak kullanıldığı çalışmada yük tanıma doğruluğunun iyileştiği görülmüştür. [10]'da yük tanıma için konvolüsyonel sinir ağlarının kullanılmasını önermişlerdir. Çalışmada güç sinyalindeki değişimler, bir türev alma işlemi ile belirlenmiş ve önerilen metot için girdi olarak kullanılmıştır. Ayrıca kullanılan veriden elde edilen bazı istatistiksel bilgiler de modelin girdisi olarak kullanılmıştır. Gerçekleştirilen simülasyon çalışmaları, önerilen yöntemin başarısını ortaya koymuştur. [11]'de yükleri sınıflandırmak ve tanımak için C ortalamalar (C-means) algoritmasının kullanılmasını önermişlerdir. 
Çalışmada öznitelik olarak enerji güç miktarlarının yanında akım değerleri de kullanılmıştır. Bir sağlık tesisinden toplanan veriler üzerinde yapılan çalışmalarda, yüksek tanıma doğruluğu değerleri elde edilmiştir. [17]'de KuhnMunkras algoritmasının iyileştirilmiş bir versiyonu olan bir olay eşleştirme algoritması önermişlerdir. Yöntemde öncelikle bir cihazın devreye girip çıkması durumu belirlenir. Sonra aktif-reaktif güç sinyalleri gibi öznitelikler bir sınıflandırıcı ile sınıflandırılarak, Kuhn-Munkras algoritması ile yükün tanınması gerçekleştirilir. REDD veri seti üzerinde yapılan deneyerde başarılı yük tanıma performansı elde edilmiştir. [18]'de yük tanıma için kuantum parçacık sürü optimizasyonu (quantum particle swarm optimization) algoritmasına dayalı bir yöntem kullanılması önermişlerdir. Çalışmada öncelikle elektrikli cihazları temsil edecek öznitelikler elde edilmiş, sonra kuantum parçacık sürü optimizasyonu algoritması ile elektrikli cihazların tanınması işlemi gerçekleştirilmiştir. 8 farklı elektrikli ev cihazı üzerinde yapılan çalışmalarda başarılı sonuçlar elde edilmiştir. [13]'te yaptıkları çalışmada, bir binada devrede olan yükleri tanımak için, binanın güç tüketimlerini analiz etmişlerdir. Çalışmada öncelikle bir öznitelik seçim yöntemi kullanılarak, veri daha küçük bir forma indirgenmiştir. Böylelikle hesaplama zamanı azaltılarak kullanılacak yöntem, gerçek zamanlı uygulamalar için de uygulanabilir hale getirilmiştir. Sonrasında ise bir dalga şekli eşleştirme yöntemi ile kullanılan yükler tanınmaya çalışılmıştır. Gerçekleştirilen simülasyonlarda tatmin edici tanıma performansı elde edilmiştir.

Kullanılan yöntemler genellikle denetimli ve denetimsiz yöntemler olmak üzere iki farklı kategoride değerlendirilir [5]. Denetimli yöntemler sınıfların öğrenilmesi için bir eğitim safhasına ihtiyaç duyarken, iyi bir tanıma performansı sağlarlar. Denetimsiz yöntemler, denetimli yöntemlere kıyasla daha kolay uygulanabilirlerdir [6]. Bu sebeple sunulan çalışmada, bu alandaki başarısı dikkate alınarak, yük tanıma için yapay sinir ağları kullanılmıştır. Öncelikle Afyon Kocatepe Üniversitesi laboratuvarlarında 5 farklı elektrikli ev aleti ve bunların farklı kombinasyonları ile deneyler gerçekleştirilmiş, deneylerde ölçülen akım ve gerilim değerleri kaydedilmiştir. Bu kapsamda, sistemde aynı anda 1, 2 ve 3 yükün bulunduğu toplamda 180 deney gerçekleştirilmiştir. 18 farklı kombinasyon için 10'ar deney yapılmış, böylece deneyler arasında oluşabilecek farklılıklar da dikkate alınmıştır. Öznitelik olarak akım sinyalinden elde edilen harmonik akımlar kullanılmış ve oluşturulan modelin başarısı irdelenmiştir. Bu makalenin organizasyonu aşağıdaki şekilde tasarlanmıştır. 2. Bölümde çalışmada kullanılan verilerin nasıl elde edildiğinden ve yük tanımada kullanılan modelin detaylarından bahsedilmiştir. 3. Bölümde deney sonuçları verilmiş ve son olarak 4. Bölümde sonuçlar tartışılmıştır.

\section{MATERYAL VE METOT}

Bu çalışmada kullanılan veriler, Afyon Kocatepe Üniversitesi Mühendislik Fakültesi laboratuvarlarında 5 farklı elektrikli cihazdan elde edilmiştir. Bu kapsamda 1000W gücünde bir elektrik süpürgesi, 1200W gücünde bir 1sitıc1, 1000W gücünde bir 1sitıc1, 2200W bir su 1sitıcı ve 2100W bir ütü tak-kullan elektrikli cihazlar (yükler) olarak seçilmiştir. Çalışmada amaç hem bireysel yükleri tanımak hem de sistemde herhangi bir anda mevcut yükleri doğru bir şekilde ayrıştırmaktır. Bu amaçla, Şekil 1'de görüldüğü gibi hem bireysel yükler (Şekil 1a) hem de farklı yük kombinasyonları (Şekil 1b) ile deneyler yapılmıştır. Buradan da görüldüğü gibi $220 \mathrm{~V}$ bir AC kaynaktan beslenen yük üzerine düşen gerilim ve üzerinden akan akım değerleri toplanarak kaydedilmiştir. Ölçümler için bir Fluke marka akım probu, Pintek marka voltaj probu ve Siglent marka bir osiloskop (SDS1102CNL) kullanılmıştır. Akım ve gerilim probu ile, yüksek örnekleme oranıyla (250kS / sn) anlık akım ve gerilim değerleri algılanmış, her ikisi de bir osiloskopa bağlanmış ve veriler CSV formatında kaydedilmiştir. Yukarıda belirtilen 5 yük bireysel ve bu yüklerin 2'li (9 farklı kombinasyon) ve 3'lü (4 farklı kombinasyon) kombinasyonlarında oluşan ve her kombinasyon için 10 deneyin yapıldığ 1 toplam 180 deney gerçekleştirilmiştir. Her bir deney için 10000 veri noktasından oluşan 2 periyotluk akım ve gerilim sinyalleri elde edilmiştir. Çalışmada öznitelik çıkarmak için sadece akım sinyali kullanılırken, gerilim sinyalinden, sadece 5000 veri noktasından oluşan 1 periyotluk akım sinyalini elde etmek için faydalanılmıştır.

Bu çalışmada, yapay sinir ağlarına dayalı bir yük tanıma modelinin kullanılması önerilmiştir. İlk aşama, öznitelik çıkarma işlemidir. Bunun için öncelikle bir veri önişleme süreciyle bir periyotluk akım sinyali, 2 periyotluk sinyalden ayrılır. Akım sinyalinin Fourier Transformundan, harmonik akım değerleri elde edilir. Bu kapsamda 1. (temel frekans), 3., 5., 7., 9. ve 11. Harmonik akımları kullanılacak öznitelikler olarak seçilmiştir. Harmonik akımların ayırt ediciliğinin kabaca değerlendirilmesi adına örnek olarak yapılan tüm deneylerden elde edilen 3. Harmonik akım değerlerinin değişimini gösteren grafik Şekil 2'de sunulmuştur. 

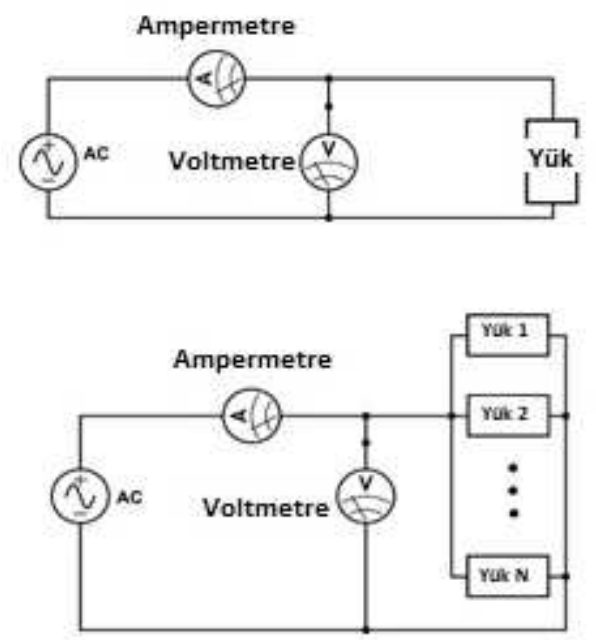

Şekil 1. Kurulan test düzeneği prensip şeması a) tek yük (üst) durumu b)yük kombinasyonu durumu (alt)

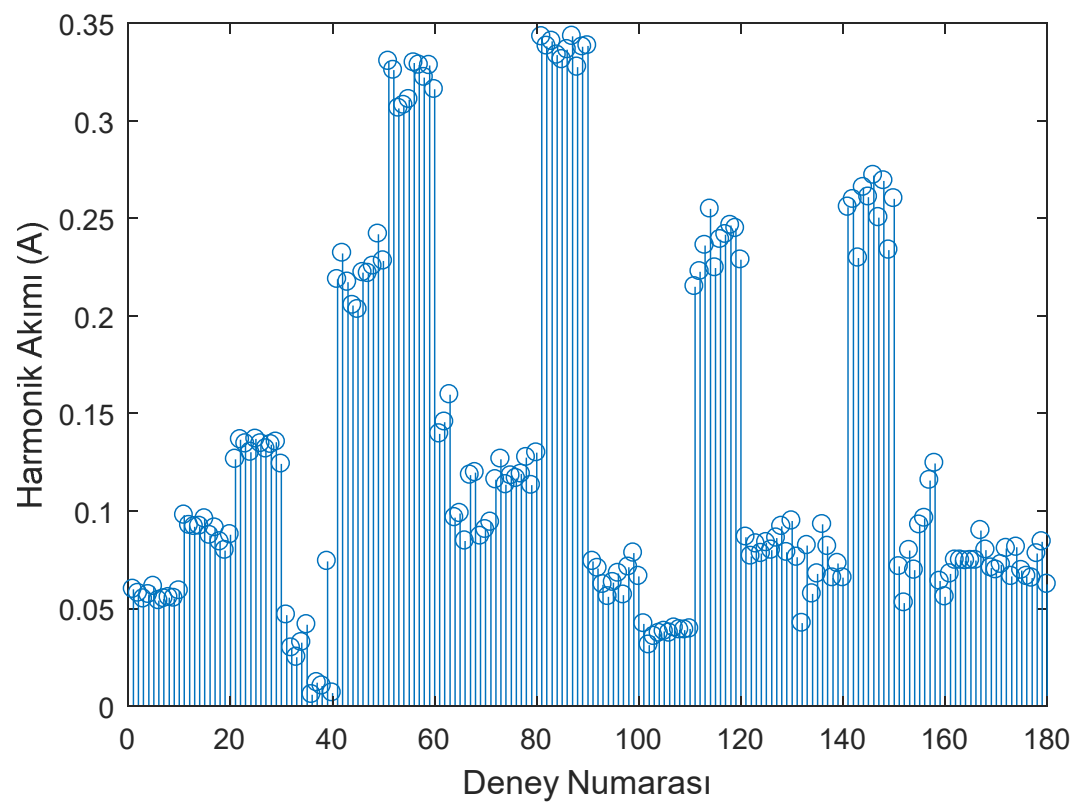

Şekil 2. Yüklerle yapılan deneylerden elde edilen 3. Harmonik akım sinyalleri

Şekil 2 incelendiğinde, bu verinin oldukça ayırt edici olduğu görülmektedir ancak belirli değerler birbirlerine oldukça yakındır. Örneğin son iki kombinasyonla yapılan deneylerden elde edilen 3. Harmonik akımı değerleri birbirine çok yakındır. Dolayısıyla bunları birbirinden ayırt edebilmek için farklı sinyallere de ihtiyaç vardır. Bu sebeple temel frekans akımı dahil 6 farklı harmonik akımı $(1,3,5,7,9,11)$ bu çalışmada değerlendirilmiştir. Bunların dışındaki yüksek dereceli harmonik akımların değerleri oldukça düşük olduğundan ayırt etmede kullanılması fayda sağlamayacağı değerlendirilmiştir. Öznitelikler çıkarıldıktan sonra bir sınıflandırıcı vasıtasıyla yükler sınıflandırılarak, tanımlanır. Bu çalışmada yapay sinir ağlarının kullanılması uygun görülmüştür. Yapay sinir ağları (YSA) insan beyninin çalışma prensibini model alan bir yöntemdir. YSA geleneksel olarak üç veya daha fazla tabakadaki nöronlardan oluşur. Veri ağa giriş katmanından girer, bir veya daha fazla gizli katmandan geçer ve çıkış katmanından çıkar. Her katmandaki düğümler, sonraki katmandaki 
düğümlere bağlanır. Her gizli katman ve çıktı katmanı düğümü, üstündeki düğümlerden veri toplar ve bir aktivasyon işlevi uygular [19,20]. Bir aktivasyon fonksiyonu çıkışın genliğini sınırlamak için kullanılır. İleri besleme işleminde veriler ağ üzerinden ileri yönde beslenir ve hata geriye doğru yayılır. Ağırlıkların ve sapmaların değerleri bir eğitim süreciyle belirlenir ve çıktı istenen bir doğruluğa ulaşana kadar geri yayılma tekrarlanır. Bu çalışmada, 6 farklı harmonik akımı öznitelik olarak kullanıldığı için oluşturulan modelde 6 girişi ve 5 farklı yüke ait kombinasyonlar kullanıldığı için ise 5 çıkışı bulunan Şekil 3'teki gibi bir YSA modeli tasarlanmıştır.

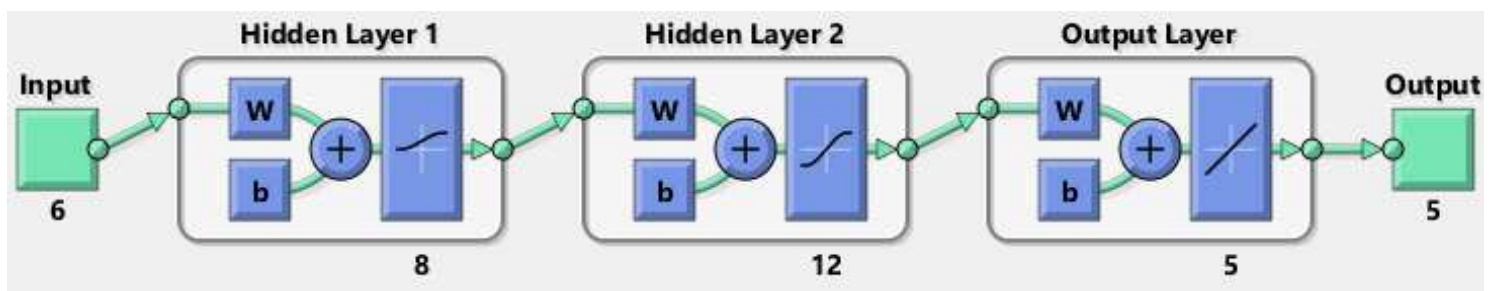

Şekil 3. Çalışmada kullanılan bir YSA modeli için prensip şeması

\section{BULGULAR VE TARTIŞMA}

$\mathrm{Bu}$ çalışmada tak kullan elektrikli cihaz yükü tanıma için öznitelik çıkarma ve sınıflandırma aşamalarından oluşan bir yük tanıma modeli önerilmiştir. Afyon Kocatepe Üniversitesi Mühendislik Fakültesi laboratuvarında 5 farklı tak kullan elektrik cihazı kullanılarak 180 deney yapılmış ve bu deney verileri kullanılarak tanıma işlemi gerçekleştirilmiştir. Öznitelik çıkarma yöntemi olarak literatürde en fazla sinyalin fourier dönüşümünden faydalanıldığı görülmüş ve bu çalışmada da bu yöntemden faydalanılmıştır. Matlab'ın FFT Analiz toolbox'1 kullanılarak 1., 3., 5., 7., 9. ve 11. Harmonik akım değerleri hesap edilmiş ve çalışmada öznitelik olarak kullanılmıştır. Sınıflandırıcı olarak ileri beslemeli geri yayılmalı yapay sinir ağlarının kullanılması kararlaştırılmış ve çeşitli denemelerden sonra uygun ağ topolojisine karar verilmiştir. Gerçekleştirilen çalışmada oluşturulan modelin başarısı Eşitlik 1. ile değerlendirilmiştir.

$$
\text { Başarı }(\%)=\frac{\text { Doğru sınıflandırma sayısı }}{\text { Toplam deney sayısı }} \times 100
$$

Gerçekleştirilen 180 deney verisinden 110 tanesi eğitim için kullanılırken, 70 tanesi test için kullanılmıştır. Yapay sinir ağları için eğitimde ve testte kullanılan verilerin farklılığının, simülasyon sonucunu değiştirebileceği de dikkate alınarak, eğitim ve test verileri rastgele seçilmiş ve her simülasyon 5 kere tekrarlanmıştır. 5 simülasyon sonucu elde edilen sonuçlar ortalama ve standart sapma ile ifade edilmiştir. İlk aşamada 6 girişten oluşan ağ, 5 yük kullanıldığı için 5 çıkıştan oluşmaktadır. Sistemde bulunan cihazlar için çıkış 1, bulunmayanlar için çıkış sıfır olacaktır. 8 ve 12 nörondan oluşan 2 gizli katman planlanmış, bu gizli katmanlar için logsig ve tansig aktivasyon fonksiyonları kullanılırken, çıkış için doğrusal aktivasyon fonksiyonu kullanılmıştır. Seçilen tüm harmonik değerlerin kullanıldığı çalışmada Tablo 1'de sunulan sonuçlar elde edilmiştir. $\mathrm{Bu}$ sonuç önerilen modelin başarısını ortaya koymaktadır. Harmonik akım sinyalleri yük tanımada ayırt edici özellik sağlar ve yapay sinir ağları yük tanıma için iyi bir sınıflandırıcıdır. Çalışmanın ikinci aşamasında ise hangi harmonik sinyallerin bu uygulamada yük tanıma için daha etkili olduğu araştırılmıştır. Bu kapsamda, bir özniteliğin etkisini belirlemek için her deneyde 1 öznitelik devreden çıkarılmış ve başarının bundan nasıl etkilendiği gözlenmiştir. Şayet girdi setinden çıkan bir öznitelik, tanıma başarısını olumsuz etkiliyor ise bu öznitelik önemli değilse daha önemsiz olarak değerlendirilmiştir. Bu aşamada 3'er deneyin değişimi anlamada yeterli olacağı düşünülmüştür. Sadece girdi sayısının değiştiği, ağ topolojisinin değişmediği yapıda elde edilen deney sonuçları Tablo 2'de sunulmuştur. 


\begin{tabular}{|c|c|c|}
\hline & $\begin{array}{l}\text { BŞEÜ Fen Bilimleri Dergisi } \\
7(1), 452-460,2020\end{array}$ & $\begin{array}{r}\text { BSEU Journal of Science } \\
\text { DOI: } 10.35193 / \text { bseufbd.736206 }\end{array}$ \\
\hline$\ddot{U}$ & & 58-7575 (http://dergipark.gov.tr/bseufbd) \\
\hline
\end{tabular}

Tablo 1. 1-3-5-7-9-11. Harmonik akımları ile elde edilen performans değerleri

\begin{tabular}{ccc}
\hline Model & Ortalama Başarı (\%) & Standart Sapma \\
\hline YSA (1-3-5-7-9-11. harmonikler) & 93.14 & 3.66 \\
\hline
\end{tabular}

Tablo 2. Her bir harmonik akımı girdi setinden çıkarılınca performansın değişimi

\begin{tabular}{ccc}
\hline Model & Ortalama Başarı (\%) & Standart Sapma \\
\hline YSA (3-5-7-9-11. harmonikler) & 90.96 & 8.25 \\
YSA (1-5-7-9-11. harmonikler) & 85.24 & 3.59 \\
YSA (1-3-7-9-11. harmonikler) & 96.19 & 4.36 \\
YSA (1-3-5-9-11. harmonikler) & 97.14 & 1.43 \\
YSA (1-3-5-7-11. harmonikler) & 94.29 & 2.95 \\
YSA (1-3-5-7-9. harmonikler) & 94.29 & 2.86 \\
\hline
\end{tabular}

Tablo 2 incelendiğinde, 3. Harmonik girdi setinden çıkarıldığında, başarıda önemli bir düşüş olduğu görülmüş ve bu nedenle 3. Harmonik en önemli öznitelik olarak seçilmiştir. Daha sonra başarıda en yüksek ikinci düşüş 1. Harmonik veri setinden çıkarılınca gerçekleşmiş, bu sebeple 1. Harmonik en önemli 2. öznitelik olarak belirlenmiştir. En önemli 3. öznitelik ise 11. Harmonik olarak belirlenmiştir. 9. ve 11. Harmonik girdi setinden çıkarılınca ortalama başarılar aynıdır ancak 11. Harmonik için standart sapmanın daha düşük olması sebebi ile bu veri daha önemli olarak seçilmiştir. Bu seçimin doğruluğunu test etmek amaciyla daha önemli olarak belirlenen 3 harmonik verisi ile, daha az önemli olduğu belirlenen 3 harmonik sinyal ile yük tanıma modeli kurulmuş ve sonuçlar Tablo 3'te karşılaştırılmıştır.

Tablo 3. Seçilen ve seçilmeyen öznitelikler ile performans sonuçları

\begin{tabular}{lcc}
\hline Model & Ortalama Başarı (\%) & Standart Sapma \\
\hline YSA (1-3-11. harmonikler) & 89.52 & 2.97 \\
YSA (5-7-9. harmonikler) & 64.76 & 9.07 \\
\hline
\end{tabular}

Tablo 3'ten de açıkça görüleceği gibi seçilen 3 özniteliğin (1., 3. ve 11. Harmonik) kullanıldığ1 modelde, daha az önemli olarak belirlenmiş özniteliklerle kurulan modele göre çok daha başarılı sonuçlar elde edilmiştir. Burada yapılan seçim, çalışmada kullanılan cihazlara bağlı olarak değişebilir. Tablo 1 ve Tablo 3 'te sunulan sonuçlar karşılaştırıldığında, 6 girdi yerine 3 girdi kullanılan çalışmada başarıda önemli bir düşüş görülmeden yine başarılı sonuçlar elde edildiği gözlenmiştir. Ayrıca gerçekleştirilen tüm simülasyon çalışmaları dikkate alındığında, harmonik bileşenlerin yük tanımada kullanılabilecek önemli öznitelikler olduğu açıkça görülmektedir. Çalışmada hem benzer karakteristiğe sahip yükler (farklı iki güçte 1sıtıcı) hem de benzer güçte yükler (süpürge ve 1sıtıcı gibi) bulunmaktadır ki, bu da tanıma işlemini zorlaştırmaktadır. Ancak deney sonuçları, tasarlanan modelin bu zorluğun üstesinden geldiğini göstermektedir. 1., 3. ve 11. Harmonik akımları daha önemli öznitelikler olarak belirlenmiştir. Burada 1. ve 3. Harmonik akımlarının ayırt edici olması beklenen bir sonuç iken, 11. Harmonik akımın 5, 7 ve 9. Harmonik akımdan daha ayırt edici olması şaşırtıcıdır. Harmonik akımların derecesi yükseldikçe değerleri düştüğü için belirli bir dereceden sonra harmonik akımlar dikkate alınmazlar. Ancak bu sonuç belirli harmonik akımların değerleri düşmesine rağmen ayırt edici olabileceklerini göstermektedir. Bu çalışmada kullanılan yükler için bu seçim gerçekleştirilmiştir, farklı yükler için seçim sonuçlarının değişebileceği düşünülmektedir. Çünkü bir ısıtıcını üreteceği harmonik ile bilgisayar gibi dönüştürücü kullanan bir cihazın üreteceği harmonik farklı olacaktır. Bu sebeple öznitelik seçim işlemi her yeni yük ile tekrar yapılmalı ve yeni yüke göre tekrar revize edilmelidir. Harmonik sinyaller daha önce literatürde farklı amaçlar doğrultusunda 
kullanılmıştır ancak böyle bir yaklaşım ile özniteliklerin önemi araştırılmamıştır. Bu durum dikkate alındığında çalışmanın önemi daha iyi anlaşılmaktadır.

\section{SONUÇLAR}

Yapılan çalışmada, bir meskende sıklıkla kullanılan çeşitli tak-kullan elektrikli cihaz yüklerinin tanınması için yeni bir model geliştirilmiştir. 1000W 1sıtıc1, 1200W 1sıtıc1, 1000W elektrikli süpürge, su 1sıtıcısı ve ütünün yük olarak kullanıldığı çalışmalarda, bu yüklerin bireysel ve çeşitli kombinasyonlar halinde devrede oldukları durumda akım ve gerilim değerler ölçülerek kaydedilmiştir. Daha sonra akım sinyalinin fourier dönüşümünden harmonik bileşenler hesap edilmiş ve bu bileşenlerin yük tanıma başarısına etkisi incelenmiştir. Yapay sinir ağlarının sınıflandırıcı olarak kullanıldığı model ile yapılan çalışmalarda, kullanılan yükler için 1., 3 . ve 11 . Harmonik bileşenlerin, tanıma başarısına 5., 7. ve 9. Harmonikten daha fazla etki ettiği tespit edilmiştir. Bu tespitin doğruluğunu ispat etmek için de simülasyon çalışması yapılarak, tespitin doğruluğu gösterilmiştir. Deney sonuçları hem harmonik sinyallerin bu alanda kullanılmak için iyi birer öznitelik olduğunu göstermiş, hem de oluşturulan modelin bu amaç için oldukça başarılı bir model olduğu ortaya konulmuştur. Kullanılan öznitelik seçim stratejisi sayesinde hem işlem yükü azaltılmış hem de tanıma başarısında önemli bir kayıp gözlenmemiştir. Kullanılan yük tipine bağlı olarak yük tanıma için harmonik akımların önem sırası değişebilecektir. Bu sebeple öznitelik seçim stratejisinin yük tanıma algoritmasına entegre edilmesi daha uygun olacağı düşünülmüş ve bu konu gelecek çalışmalar için bir araştırma konusu olarak değerlendirilmiştir.

\section{KAYNAKLAR}

[1] Hart, G. W. (1992). Nonintrusive Appliance Load Monitoring. Proceedings of the IEEE, 80(12), 18701891. https://doi.org/10.1109/5.192069

[2] Du, L., Restrepo, J. A., Yang, Y., Harley, R. G., \& Habetler, T. G. (2013). Nonintrusive, self-organizing, and probabilistic classification and identification of plugged-in electric loads. IEEE Transactions on Smart Grid, 4(3), 1371-1380. https://doi.org/10.1109/TSG.2013.2263231

[3] Chang, H. H., Lian, K. L., Su, Y. C., \& Lee, W. J. (2014). Power-spectrum-based wavelet transform for nonintrusive demand monitoring and load identification. IEEE Transactions on Industry Applications, 50(3), 2081-2089. https://doi.org/10.1109/TIA.2013.2283318

[4] Giri, S., \& Bergés, M. (2015). An energy estimation framework for event-based methods in Non-Intrusive Load Monitoring. Energy Conversion and Management, 90, 488-498.

https://doi.org/10.1016/j.enconman.2014.11.047

[5] Lin, S., Zhao, L., Li, F., Liu, Q., Li, D., \& Fu, Y. (2016). A nonintrusive load identification method for residential applications based on quadratic programming. Electric Power Systems Research, 133, 241-248. https://doi.org/10.1016/j.epsr.2015.12.014

[6] Lu, H., Xin, W., Hui, B., Bing, Q., \& Aixia, Z. (2016). A residential load identification algorithm based on periodogram for non-intrusive load monitoring. In China International Conference on Electricity Distribution, CICED (Vol. 2016-September). IEEE Computer Society. https://doi.org/10.1109/CICED.2016.7576286

[7] Cominola, A., Giuliani, M., Piga, D., Castelletti, A., \& Rizzoli, A. E. (2017). A Hybrid Signature-based Iterative Disaggregation algorithm for Non-Intrusive Load Monitoring. Applied Energy, 185, 331-344. https://doi.org/10.1016/j.apenergy.2016.10.040

[8] Liu, B., Luan, W., \& Yu, Y. (2017). Dynamic time warping based non-intrusive load transient identification. Applied Energy, 195, 634-645. https://doi.org/10.1016/j.apenergy.2017.03.010

[9] Dvorkin, D., Palis, S., Silaev, M., \& Tulsky, V. (2017). Balanced load identification based on the correlation of the phase currents. In 58th Annual International Scientific Confererence on Power and Electrical Engineering of Riga Technical University, RTUCON 2017 - Proceedings (Vol. 2017-November, 
pp. 1-4). Institute of Electrical and Electronics Engineers Inc. https://doi.org/10.1109/RTUCON.2017.8124822

[10] Buddhahai, B., Wongseree, W., \& Rakkwamsuk, P. (2018). A non-intrusive load monitoring system using multi-label classification approach. Sustainable Cities and Society, 39, 621-630. https://doi.org/10.1016/j.scs.2018.02.002

[11] Liu, Y., Wang, X., Zhao, L., \& Liu, Y. (2018). Admittance-based load signature construction for nonintrusive appliance load monitoring. Energy and Buildings, 171, 209-219. https://doi.org/10.1016/j.enbuild.2018.04.049

[12] Zhang, Y., Yang, G., \& Ma, S. (2019). Non-intrusive load monitoring based on convolutional neural network with differential input. In Procedia CIRP (Vol. 83, pp. 670-674). Elsevier B.V. https://doi.org/10.1016/j.procir.2019.04.110

[13] Guillén-García, E., Morales-Velazquez, L., Zorita-Lamadrid, A. L., Duque-Perez, O., Osornio-Rios, R. A., \& Romero-Troncoso, R. de J. (2019). Identification of the electrical load by C-means from non-intrusive monitoring of electrical signals in non-residential buildings. International Journal of Electrical Power and Energy Systems, 104, 21-28. https://doi.org/10.1016/j.ijepes.2018.06.040

[14] Xiao, Y., Hu, Y., He, H., Zhou, D., Zhao, Y., \& Hu, W. (2019). Non-Intrusive Load Identification Method Based on Improved KM Algorithm. IEEE Access, 7, 151368-151377. https://doi.org/10.1109/ACCESS.2019.2948079

[15] Ding, G., Wu, C., Wang, Y., Liang, Y., Jiang, X., \& Li, X. (2019). A novel non-intrusive load monitoring method based on quantum particle swarm optimization algorithm. In Proceedings - 2019 11th International Conference on Measuring Technology and Mechatronics Automation, ICMTMA 2019 (pp. 230-234). Institute of Electrical and Electronics Engineers Inc. https://doi.org/10.1109/ICMTMA.2019.00058

[16] Hamdi, M., Messaoud, H., \& Bouguila, N. (2020). A new approach of electrical appliance identification in residential buildings. Electric Power Systems Research, 178, 106037. https://doi.org/10.1016/j.epsr.2019.106037

[17] Zoha, A., Gluhak, A., Imran, M. A., \& Rajasegarar, S. (2012, December). Non-intrusive Load Monitoring approaches for disaggregated energy sensing: A survey. Sensors (Switzerland). https://doi.org/10.3390/s121216838

[18] Xu, L., Wang, S., \& Tang, R. (2019). Probabilistic load forecasting for buildings considering weather forecasting uncertainty and uncertain peak load. Applied Energy, 237, 180-195. https://doi.org/10.1016/j.apenergy.2019.01.022

[19] Akarslan, E., Hocaoğlu, F. O., \& Ucun, I. (2017). Classification of disc damage status by discovering knowledge from experimental data in marble cutting process. Proceedings of the Institution of Mechanical Engineers, Part C: Journal of Mechanical Engineering Science, 231(13), 2407-2416. https://doi.org/10.1177/0954406216634748

[20] Ghiassi, M., \& Burnley, C. (2010). Measuring effectiveness of a dynamic artificial neural network algorithm for classification problems. Expert Systems with Applications, 37(4), 3118-3128. https://doi.org/10.1016/j.eswa.2009.09.017 